\section{Academic general practice}

At the time of the introduction of the charter for general practice ten years ago only Edinburgh University had fully recognised the potential of general practice as a clinical academic discipline. One may argue whether the espousal of the cause by the UGC in its guidelines for developments in the 1972-7 quinquennium accelerated change or simply reflected a trend already under way; but today the presence of departments of general practice or equivalent subunits within departments of medicine or community medicine in almost all the major British medical schools is beyond debate. So far, however, judgments of the success of these departments have tended to reflect assessments of personalities rather than organised evaluations of the contribution to medical education and progress made by the units as such.

Assessment of academic respectability is an infrequently applied and inconsistent science. The major disciplines have achieved immunity from the process through the ordered defences of tradition, and many of the more recently established specialties appear to offer such indispensable clinical or technical expertise that only those inviting ostracism from the communion table will question their colleagues' rights to independent recognition. Lacking protection on either of these grounds, academic general practice has been required to defend its validity and credibility to an unusual (though healthy) degree. In the absence of agreed criteria of academic stature the issues have rarely been clearly presented. Professor Richardson's paper ( $p$ 740) on the value of a university department of general practice is a timely and welcome contribution to the debate. In a predictably well-argued case Richardson proposes four criteria to be met for a subject to gain academic independence. Firstly, the subject must encompass a substantial and distinct area of clinical practice: we know that four out of five illnesses seen in general practice never reach hospital care, while the reasons for patients reaching hospital are more complex than severity of morbidity alone. Secondly, the subject must teach skills in defining and managing problems that are not available elsewhere: in general practice we may see decision-making in predominantly self-limiting illness, the use of time as an investigation, the unravelling of physical and psychological components of illness, and the art of diagnosing absence of illness without referral-only some of the many techniques little taught elsewhere. The discipline must, thirdly, have a recognisable philosophy: the degree of the general practitioner's concern with the whole patient as against the disease is probably his hallmark, though Richardson correctly emphasises that general practitioners have no more monopoly on humanity than hospital specialists have on clinical competence. Finally, the subject must be able to support active research requiring powers of critical selfanalysis, of experimental thinking, and of active progressive development: steady progress is being made here, and there is already a healthy awareness of the difficulties facing research workers in general practice. ${ }^{1}$

The honeymoon period is over now for academic general practice. Where euphoria existed it has been tempered, and where resistance was present acceptance is growing. The vocational training programmes that have become established throughout Britain and which are an integral part of academic practice have helped to shape medical attitudes. If the profession has its way vocational training may soon be a legal requirement for NHS principals. If Richardson's criteria of academic suitability are fair ones general practice is as entitled to pass their scrutiny as is any other clinical discipline. If given the necessary support academic general practice can in the next decade make a much increased contribution to the widely based undergraduate and graduate clinical training envisaged by Merrison. It can combine research and service roles, helping to evaluate the indications for referral to the continually maturing specialist services and contributing a constructive voice to the debate on priorities for allocation of resources in the health and social services. But this new specialty needs equality of status and opportunity with other clinical disciplines, and indifference to this need will affect the morale of the pioneers as well as the critically important recruitment of able younger doctors.

${ }^{1}$ British Medical fournal, 1975, 3, 3.

\section{Dyslexia}

In everyday language "dyslexia" has come to describe severe reading difficulty, usually associated with spelling difficulty also. An inability to read and spell presents great problems to a child's educational progress and future work: so it is right and understandable that dyslexia should cause concern and should receive publicity-but unfortunate that the term and its variations should create confusion.

One problem has been the use of the term specific dyslexia (also known as development dyslexia). The World Federation of Neurology definition" of this disorder was "difficulty in learning to read despite conventional instruction, adequate intelligence, and sociocultural opportunity. It is dependent upon fundamental cognitive disabilities which are frequently of constitutional origin." This definition has come under so much criticism in the last five years that many doubt whether specific dyslexia actually exists.

In Britain the studies of Rutter and Yule ${ }^{2}$ have been valuable in reassessing the problem. Epidemiological research has shown that there are two main types of reading disorder: general reading backwardness, and specific reading retardation. General reading backwardness affects both boys and girls and is found most often in children who have other learning problems. Abnormal neurological findings are common, and disorders of motor, constructional, and speech function frequent. This condition is usually seen in children from large families and lower social classes. Specific reading retardation, on the other hand, is three times as common in boys as girls and is rarely associated with neurological abnormality. These children are average or good at other school skills such as mathematics, though they do have an increased incidence of speech problems compared with a normal control group.

Children with specific reading retardation clearly have some of the features of specific dyslexia, notably that their reading skill is disproportionately below their other skills and chronological age. But they do not have all the features listed in the classical definition of specific dyslexia, which is why many experts would prefer not to use a term that implies a single entity and a constitutional origin. While there may be a constitutional reason for specific reading retardation, there is every reason to believe that other influences are important and that it is likely to be of multifactorial origin. The condition was present in $3.5 \%$ of 10 -year-old children in the Isle of Wight compared with over $6 \%$ of London 10-yearolds. ${ }^{2}$ Others features of the child such as poor concentration 
and impulsiveness, together with adverse school influences such as high teacher turnover, combine to exacerbate and perpetuate the problem.

The educational and remedial implications of the two types of disorder are uncertain. They are likely to be important, for, though both groups have problems and need help, the backward reader is functioning at an appropriate level for himself whereas the child with specific reading difficulty is underachieving to an important extent. The secondary emotional problems must be different for the two groups, and probably the remedial therapy should be different also.

What are the implications for the doctor or teacher ? Firstly, any child whose reading is two years or more behind his chronological age should be assessed by an educational psychologist, a doctor, and probably a social worker. This assessment should be made during the primary school years in the hope that early identification and classification of the problem will allow better understanding and help for the child both family and school.

\footnotetext{
${ }^{1}$ Critchley, M, The Dyslexic Child. Springfield, Thomas, 1970.

${ }^{2}$ Rutter, M, and Yule, W, fournal of Child Psychology and Psychiatry, $1975,16,181$.
}

\section{Differential diagnosis of the hepatic porphyrias}

Hepatic porphyria is usually diagnosed on the basis of clinical findings and the measurement of porphyrins and their precursors in urine and faeces. ${ }^{1}$ In practice, porphyria presents in two main ways: as an acute disease with abdominal pain, vomiting, and neuropsychiatric manifestations; and (the cutaneous type) as a photosensitising disease of the skin. In the acute presentation it is essential to examine the urine for $\delta$-aminolaevulic acid, porphobilinogen, and excess porphyrins. The faeces must also be examined for excess coproporphyrin and protoporphyrin because in both variegate porphyria (mixed porphyria) and hereditary coproporphyria there are excessive amounts of porphyrins in the faeces.

When the cutaneous manifestations of porphyria present for the first time the diagnosis should be confirmed by examination of the urine for uroporphyrin, coproporphyrin, $\delta$-aminolaevulic acid, and porphobilinogen; of the faeces for coproporphyrin and protoporphyrin; and of the blood for protoporphyrin and coproporphyrin. In the type of cutaneous porphyria which is provoked by alcohol and other hepatotoxic substances the urine contains excessive quantities of porphyrins. In other types of cutaneous hepatic porphyria, such as variegate porphyria, the amounts of faecal porphyrins will always be raised. Examination of the blood porphyrins may be the only way of diagnosing erythropoietic protoporphyria. ${ }^{2}$

More difficult to establish is the diagnosis of latent cases of porphyria, though measurement of uroporphyrinogen cosynthetase in the red cell has been shown to be useful in the recognition of acute intermittent porphyria. ${ }^{3}$ Further methods of measuring enzyme levels in the blood will probably be developed soon to help in the diagnosis of latency.

The basis of diagnosis, therefore, is the accurate measurement of porphyrin concentrations in urine, faeces, and blood, and the methods in use are many. The most commonly used-and indeed probably the most effective-are those described by Rimington, ${ }^{4}$ which depend on simple extraction techniques followed by spectrophotometric or spectrofluorimetric measurement of the porphyrin fractions thus obtained. Another proved technique for the separation of porphyrin fractions is by thin-layer chromatography. ${ }^{5}$ Other methods of porphyrin estimation have included separation on Sephadex dextran gels, ${ }^{6}$ ion exchange chromatography, ${ }^{7}$ electrophoresis, ${ }^{8}$ counter current analysis, ${ }^{9}$ magnetic circular dichroism spectroscopy, ${ }^{10}$ and atomic absorption spectrophotometry. ${ }^{11}$ One recently described method which shows great promise is high pressure liquid chromatography. ${ }^{12}$ In the measurement of porphyrin precursors the method of choice remains that of Mauzerall and Granick, ${ }^{13}$ in some cases with modifications. In the main the chromatographic techniques are excellent as research tools, but in the normal day-to-day usage in clinical biochemistry laboratories they lack the ease of operation and the throughput achievable with extraction techniques.

Since the differential diagnosis of the porphyrias depends on the varying patterns of porphyrin excretion and production, it rests ultimately on these methods for measuring porphyrins and their precursors. An addition to this diagnostic sequence was the description of the so-called $\mathrm{X}$ porphyrin by Rimington et al $^{14}$ in 1968. This is a porphyrin-peptide complex measurable by extraction techniques which may be used in the differential diagnosis of cutaneous and non-cutaneous porphyrias. ${ }^{15}$

In normal circumstances only three of the different forms of hepatic porphyria are likely to present with skin lesions: cutaneous hepatic porphyria, variegate porphyria, and hereditary coproporphyria. Of these three, moreover, only two are likely to be confused-variegate porphyria and cutaneous hepatic porphyria. Normally these may be distinguished by the lack of familial history and absence of porphyrin precursor excretion in cutaneous hepatic porphyria, despite the similarity of skin lesions in both diseases. Diagnosis is important, because the current treatment of cutaneous hepatic porphyria is venesection (which produces a fall in porphyrin production and excretion and rapid remission of cutaneous signs and symptoms ${ }^{16}$ ). Such treatment would have little effect in variegate porphyria. Elder ${ }^{17}$ has described differentiating cutaneous hepatic porphyria or porphyria cutanea tarda from the other porphyrias by the measurement of the recently described isocoproporphyrin. This method is based on a two-dimensional chromatographic separation of faecal porphyrins. Those similar techniques already described depend on the patterns of excretion as measured by chromatographic methods rather than the presence or absence of these porphyrins. ${ }^{18}$ Because of their complexity such specialised techniques, including the measurement of plasma porphyrin concentrations in cutaneous hepatic porphyria, ${ }^{19}$ should be applied only when the diagnosis is otherwise doubtful.

\footnotetext{
${ }^{1}$ Moore, M R, and Goldberg, A, in Iron in Biochemistry and Medicine, eds A Jacobs and M Worwood. London, Academic Press, 1974.

2 Beattie, A D, and Goldberg, A, in Blood and Its Disorders, eds R M Hardisty and D J Weatherall. Oxford, Blackwell, 1974.

${ }^{3}$ Meyer, U A, et al, New England fournal of Medicine, 1972, 286, 1277.

${ }^{4}$ Rimington, C, Association of Clinical Pathologists Broadsheet No 70, 1971.

5 Doss, M, South African fournal of Laboratory and Clinical Medicine, $1971,17,221$.

${ }^{6}$ Rimington, C, and Belcher, R V, fournal of Chromatography, 1967, 28, 112.

${ }^{7}$ Doss, M, and Schmidt, A, Zeitschrift für klinische Chemie und klinische Biochemie, 1971, 9,99.

${ }^{8}$ Fischl, J, et al, Clinical Chemistry, 1970, 16, 331.

9 Barnes, H D, South African Fournal of Laboratory and Clinical Medicine, $1963,9,177$.

10 Kalman, S M, et al, Analytical Biochemistry, 1973, 52, 83.

11 Bourdon, R, Yonger, J, and Ataie, M, Annales de Biologie Clinique, $1972,30,427$.
} 